\title{
Brain Correlates of Impulsivity in Police Officers: A Neurocognitive and Ethnological Exploration
}

\author{
Roberto E. Mercadillo* and Fernando A. Barrios
}

Institute of Neurobiology, Universidad Nacional Autónoma de México, México

\begin{abstract}
Police represents an institution that regulates the social welfare where the officers assimilate the behavioral codes to perform their functions. One of the problems identified in the police officer's behaviors refers to aggressive expressions, probably linked with impulsive reactions. In this report, we show an exploratory study to elucidate the neurocognitive correlation of impulsivity in a Mexican sample of police officers. These neural correlates were obtained during the execution of cognitive paradigms in functional magnetic resonance imaging. Brain functional data were complemented and interpreted through ethnological observations and psychometrical evaluations. Results suggest that the functional neurocognitive system regulating inhibitory reactions and impulsivity are based on moral and behavioral codes learned during the police training and practice. Aggression detected in this police department could be linked more with the perception of unfairness within the police organization but not with impulsive factors. Neurocognitive and ethnological approaches conform complementary strategies for more precise evaluation of aggressive expressions in police performance.
\end{abstract}

Keywords: Inhibition, attention, working memory, fMRI, prefrontal cortex, cingulated cortex, stroop task.

\section{INTRODUCTION}

Police represents an institution that regulates the social welfare where the officers assimilate the behavioral codes to perform this function. Absorption of these codes is based on neuro-cognitive processes elicited from the perception of a reality directly internalized by the police officer and relative to their cultural context in the police organization (Aguiar, 2006; Cruz, 2007; Terrill, Paoline, \& Manning, 2003). Nevertheless, one focal problem identified in police samples concerns aggressive behaviors, meaning a series of actions directed to harm others usually connected with strong sympathetic activation and emotional experiences of anger or rage which in humans implies the idea of impulsivity (Ramírez, 2003; Ramírez \& Andreu, 2006; Santos, Caeiro, Ferro, Albuquerque, \& Luisa Figueira, 2006; Vaughn, Howard, \& Delisi, 2008) in both normal and psychopathological individuals (Alcazar-Corcoles, Verdejo-Garcia, Bouso-Saiz, \& Bezos-Saldana, 2010; Arce \& Santisteban, 2006; Gansler, et al., 2011).

Impulsivity is influenced by personality traits and individual developmental experiences that the officers most adapt in different physical and social conditions in order to respond to aggressive manifestations (Barth, Kellner, \& Heinze, 2010; Cross, Copping, \& Campbell, 2011; Upton, Bishara, Ahn, \& Stout, 2011). Some studies have revealed that the situational stress is an aspect associated with decreasing communicational skills and with increasing experiences of anger and aggressive expressions in policemen

*Address correspondence to this author at the Institute of Neurobiology, Universidad Nacional Autónoma de México, Campus UNAM Juriquilla, Blvd. Juriquilla 3001, Querétaro, QRO, 76230. Mexico; Tel: +52(442) 2381053; Fax: +52(442) 238-1046;

E-mail: emmanuele.mercadillo@gmail.com
(Alexander \& Walker, 1994; Mearns \& Mauch, 1998; Meffert, et al., 2008; Neylan, et al., 2002; Pancheri, et al., 2002; Ronald, Curtis, \& Isaacs, 1994; Stuart, 2008). Anthropological perspectives in Mexico consider the police force a cultural group where individuals share specific life styles and codes in which the authorized function is helping others, reduce and prevent harmful situations and maintain the welfare of the society at large, based on moral and legal rules learned during a specialized training in order to acquire $\operatorname{cog}$ nitive strategies to inhibit impulsive reactions (Azaola, 2006; Cruz, 2007; Suárez de Garay, 2006; Varela, 2007).

An alternative to identify a behavioral mechanism implicating impulsivity refers to the scanning of brain activity during the execution of cognitive a task concerning basic processes which indirectly require inhibition of impulsive reactions (Raichle, 2001). In this sense, working memory and selective attention constitute two basic cognitive processes related with social cognition and influenced by some factors presented in the police quotidian functions, for example in decisions making based on top-down processes of visual environmental and social cues (Scalf, Dux, \& Marois, 2011). Working memory involves the integration of recent information necessary to perform decisions and to accomplish long term memory storages (Baddeley, 2003). In addition, prolonged stressful situations and sleep deprivation are common in the police line of work and could affect the working memory processes and inhibition of impulsivity regulated by frontal brain activity (Gohar, et al., 2009; James, et al., 2007).

On the other hand, selective attention enables better discrimination of relevant stimuli in the environment. Therefore, attention is related with several processes regulating behavior in a parallel manner, such as working memory, 
motivation, emotions and decision making. The neural networks regulating attention and inhibition involve prefrontal, parietal and cingulated cortices (Posner, Sheese, Odludas, \& Tang, 2006). The function of these brain structures could be influenced by differences in the environment resulting in high continuous stress states reverberating in aggressive behaviors (Berkowitz, 2008). Under social neuroscience premises, real and hypothetic social and cultural situations are related to brain function (Todorov, Harris, \& Fiske, 2006). Therefore, brain activity must be interpreted in conjunction with ethnological data that provides cultural and inner qualities of the individuals.

In this report we present an integrative pilot exploration to evaluate impulsivity in a sample of police officers and its relation with aggressive behaviors manifestations as was requested by their police department.

\section{ETHNOGRAPHICAL EXPLORATION AND PSY- CHOMETRICAL EVALUATION}

From cultural-cognitive perspectives it is suggested that people in a group share similar codes and understandings of the world that are internalized during experience sharing. The ethnological approach based on first-person reports became relevant to identify some perceptions directly given by the individual who experience their cultural world (D'Andrade, 2001). In the case of police departments, this approach is relevant since some officer's perception about the policing dynamics is not essentially congruent with the institutional expectations (Campbell, 1995; Suárez de Garay, 2006).

The present study focuses on a sample of police officers working on the Division of Public Safety of Nezahualcóyotl Municipality which constitutes one of the most populous municipalities of Mexico, mostly conformed by migrants from other regions of the country. Social stress at Nezahualcóyotl City results in one of the most conflictive and violent regions in the Mexican Republic (Escalante, 2009). The eastern neighboring with Mexico City, which is a different federal entity, provokes jurisdictional conflicts that complicate the control of criminal acts executed in the limit of both entities furthering the complexity of legal decision making.

During a period of eight months, we performed ethnographic observations of daily activities and semi-structured interviews to officers referring attitudes and abilities that they consider as essential to implement their institutional line of duty, the way they learn them and their influence in the officer's interpersonal relations. Arguments provided by the participants and observations recorded in field were qualitative and linguistically categorized according the abilities they require and the difficulties they perceive. Officers' arguments were contrasted with the institutional information provided by Psychological Support Unit and the Police Academy.

In reference with impulsivity and aggression, officer's stands manifest the necessity to develop abilities and attitudes that help controlling the emotional and impulsivity reactions while following the police force norms. Cognitive and emotional abilities exposed by the officers are mostly learned by self-regulation during the service and trough the imitation of partner's attitudes but not necessarily instructed at the Academy. Arguments about aggressiveness were generally mentioned in reference to interpersonal relations inside the Police Department but not in relation with the civilian society and were linked with discomfort and perception of injustice concerning the institutional hierarchies. Also, impulsivity and aggressiveness were mentioned as required attitudes to maintain the self-safeguarding and reacting in dangerous situations in a violent perceived environment of Nezahualcóyotl.

Alternatively, officers mentioned that impulsivity is restrained by their sense of duty and attitudes of help conforming personal motives and the social representation of the police institution. Following, we present examples of some statements that illustrate the officer's point of view (English verson implies a semantic translation without the colloquial speech used by the officers in Spanish):

You have to be crazy to be a police officer. You could see gunshots, detached heads, dead people and everything. Really, you have to be crazy, to be like animal (men, 31 years old).

[Para ser policía hay que estar medio loco, puede haber balazos, cabezas, muertos y de todo. En serio, hay que estar medio loco, ser medio animal]

To be in full dress uniform, implicate to be a thug's target. If you kill one of them you are done, outside and inside (of jail) (women, 32 years old).

[Estar uniformado es ser blanco de las ratas. Si matas a una no te la acabas afuera ni adentro (en la cárcel)]

They (chiefs) do not recognize your labor. It is unfair that they do not recognize your work in order to be a commander. We (basic officers) are who make the hard work (women, 35 years old).

[No te dan reconocimiento por antigüedad. Es injusto que no reconozcan tu trabajo para ser comandante; nosotros somos los que nos llevamos la friega]

A lot of individuals do not try to help others, they can not become officers. The main attitude you need is wishing for other's assistance (men, 33 years old).

[Hay muchas personas que no tratan de ayudar a los otros. Esos no pueden ser policías. Lo principal que necesitas es querer ayudar]

Based on the ethnographical data, we recruited two hundred and fifteen healthy police officers ( 77 women, 138 men; $M$ age $=33.72$ yr., $S D=1.68)$ representing the 12 institutional hierarchies, from officers to the commander-in-chief, as well as the mean of age, scholar education and period of active service presented in the Police Department. The absence of psychiatric and behavioral disorders was verified by the information provided by the Psychological Support Unit in the Police Department and through the application of the automated Mexican Version of the Symptom Check List 90. The procedure was designed according to the Ethical Principles of Psychologists and Code of Conduct proposed by the American Psychological Association (O'Donohue \& Ferguson, 2003) and the Ethical Code for Psychologists in Mexico (Sociedad Mexicana de Psicología, 2009). The protocol was executed with the ethical supervision of the Direction of the Division of Public Safety and was approved by the Institutional Review Board of the Institute of Neurobiology of the Universidad Nacional Autónoma de México. Volunteers agreed to participate in anonymous and confidential 
manner after the nature of the protocol was described and no individual was paid for his/her participation.

Participants completed a self-applied paper-pencil version of The Plutchik Impulsivity Test (Páez, et al., 1996; Plutchik \& Van Praag, 1989) which valuates the tendency to make decisions in a non reflexive manner and execute risky actions. The test includes 15 items which could be rated in a range from 0 to 4 , where " 0 " represents that the person never execute the actions presented in the statement and " 4 " represents actions always taken. A Cronbach's $\alpha=.76$ was observed in the reliability test.

A data base was created and statistical analyses were executed using the SPSS 15.0 software. Student $t$ test for independent samples comparing male and female ratings were executed to identify gender differences in the responses.

Results showed a moderate score of impulsivity (13.28 $\pm 3.66)$ which is lower than the mean observed in the civilian samples $(15.60 \pm 5.5)$ when validated this instrument in Mexico (Páez et al. 1996). No gender differences were observed.

\section{MATERIALS AND METHODOLOGY}

\section{Participants}

Eight police officers ( 4 women, 4 men; $29 \pm 3$ years old) with seven years of service and representing the mean scores of the Plutchik Impulsivity test were selected from the psychometrical evaluation applied in the Police Department of the Nezahualcóyotl participated after informed written consent. The international neuropsychiatry interview-MINI and a clinical interview were applied to verify general health and the absence of mental and neurological disorders.

\section{Cognitive Tasks}

Two cognitive paradigms or tasks were designed in the E-prime software (Psychology Software Tools, Inc. Pittsburg PA.). One paradigm consisted in a version of the Counting Stroop task in Spanish language previously tested in Mexican samples (Mercadillo, Sánchez-Rey, Sánchez-Cortazar, Ramírez \& Barrios, 2011). The Stroop paradigm is based in eliciting cognitive interference through the presentation of two categorically similar stimuli which force the individual to decide or select the relevant instruction; details in Fig. (1). The second paradigm consisted in a $N$-Back letter paradigm classically designed to measure working memory execution; details in Fig. (2).

\section{Image Acquisition and Analysis}

Anatomical and functional pulse sequences for whole brain were performed on a 3.0 Tesla Philips Achieva Scanner (Philips Medical Systems Eandhoven, NL) in the National Institute of Psychiatry. For the functional image acquisition a BOLD EPI-GRE (blood-oxygen level dependent EPI gradient echo) sequence was acquired over 30 slices, $5 \mathrm{~mm}$ thick slice with no gap and $4 \times 4 \mathrm{~mm}^{2}$ in plane resolution; $\mathrm{TR}=3000 \mathrm{~ms}, \mathrm{TE}=30 \mathrm{~ms}$, flip angle $=90^{\circ}, \mathrm{FOV}=24 \mathrm{~cm}$. All fMRI data were transferred to offline workstations using DICOM format and all the image analysis was executed using SPM5 (Welcome Department of Imaging Neuroscience, http://www.fil.ion.ucl.ac.uk/spm/).
The projection of the stimuli and the manual response were synchronized and extracted using the Lumina response system (Cedrus Co. San Pedro, CA). After acquisitions all images were transferred to an off line workstation with SPM 5 where they were: time sliced, realigned, spatially normalized and smoothed. Contrasts between conditions of interest were assessed with FWE correction with 0.05 level. The Talairach Daemon Client system (RIC, University of Texas Health Science Center) was used to acquire the specific Brodmann areas and region associated with the brain activity clusters.

\section{RESULTS}

During the Counting Stroop Task, brain activity was observed in left prefrontal cortex in Brodmann area (BA) 47 and bilateral corresponding with BA 9. Parietal activity was observed bilaterally in BA 40 while the temporal lobe was identified as active in the left Brodmann area 22. Occipital activation was identified in the cuneus corresponding with the Brodmann area 19. See Table 1 and Fig. (3).

While performing the N-Back paradigm, BOLD activations were identified in the left frontal cortex while corresponding with BA 44 and 47 and parietal in BA 7. Right BA 21 and left BA 22 were observed in temporal cortex and the cuneus in occipital region in BA 18.

\section{DISCUSSION}

Parietal and frontal activity identified during the Counting Stroop task could be related with the orienting and executive cognitive systems conforming the attentional network (Posner, et al., 2006). Nevertheless, the lack of activation in the anterior cingulated (ACC) and orbitofrontal cortex associated with the attention processes and decision making may suggest differences between the police officers in comparison with healthy civilian reports while executing the Counting Stroop task (Bush, et al., 1998; Bush, Whalen, Shin, \& Rauch, 2006). The relevance of the ACC implies reciprocal neural connections with temporal and frontal regions related with semantic and motor processes, respectively, and with parietal regions linked with sensorial integration (Koski \& Paus, 2000; Posner, Rothbart, Sheese, \& Tang, 2007; Posner, et al., 2006). Subsequently, ACC and orbitofrontal cortex functions are necessary to perform decisions and inhibit impulsive and aggressive behaviors (Adolphs, 2008; Nelson \& Trainor, 2007).

Function of ACC is also related with cognition involving reward systems influenced by developmental experiences and social habit learning (Cohen, Dunbar, \& McClelland, 1990; Mercadillo, Díaz \& Barrios, 2007). As well, the lack of cingulate activity has been related with the presence of attention deficit disorder and impulsivity (Bush, et al., 1999), nevertheless police officers did not manifest clinical symptoms linked with this disorder. Therefore, results may indicate the influence of inflexible decision making strategies learned during their police training and service, which has been similarly observed in people manifesting rigid opinions (Amodio, Jost, Master, \& Yee, 2007).

On the other hand, prefrontal activation produced by the $N$-Back paradigm, results in processes related with decision making linked to working memory (Buckner, Kelley, \& Petersen, 1999). Parietal activation may imply semantic and perceptual processes directed to analyze mnemonic stimuli 


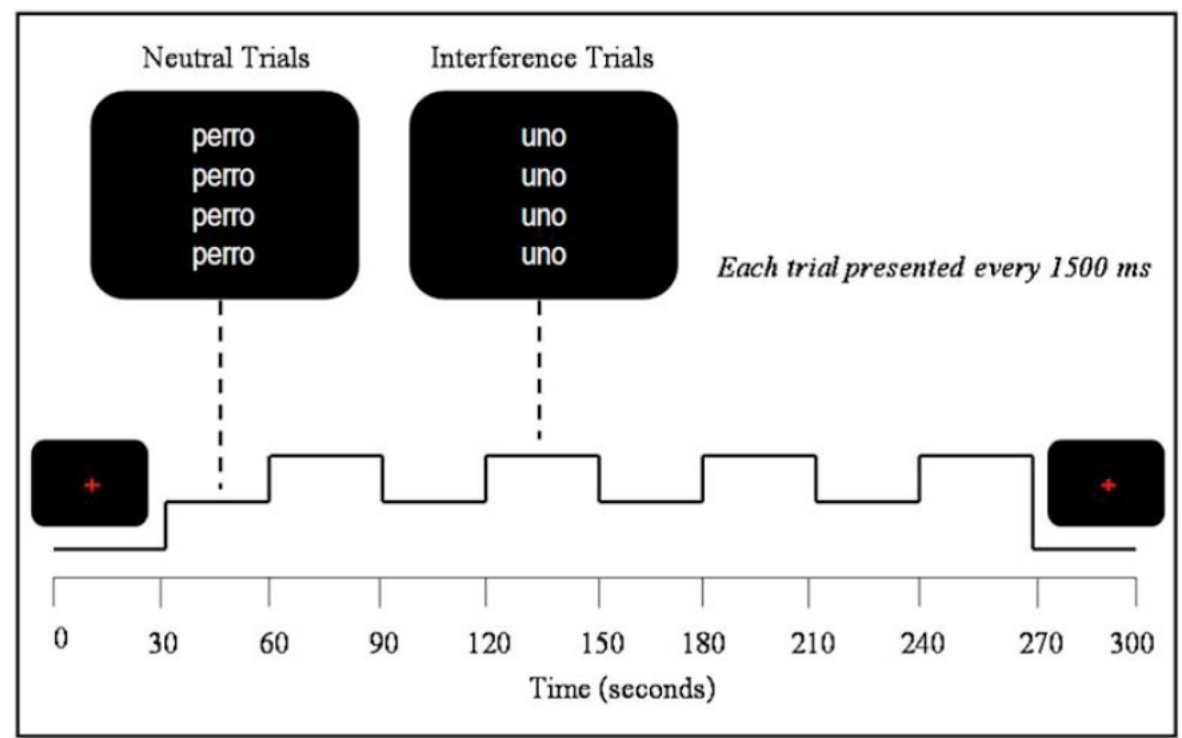

Fig. (1). Illustration of the block designed paradigm to assess the Counting Stroop Task. The task initiated with a fixation cross during 30 sec. Twenty neutral and Interference trials presented during $1500 \mathrm{~ms}$ were alternated in eight blocks with 30 sec. duration each. Neutral trials represented groups of words naming four animals: perro (dog), gato (cat), pájaro (bird) and ratón (mouse). Interference trials presented words naming numbers: uno (one), dos (two), tres (three) and cuatro (four). Each trial could be constituted by one, two, three or four words naming the same animal or number name. Participants were instructed to indicate the number of words presented in each trial and assessed the correct or incorrect answer by using the IFIS Response System (In Vivo Inc. Orlando FL) which consisted in two button settings collocated in index and middle fingers: Right middle (one), right index (two) left index (three) and left middle (four). For the example represented in this figure participant should indicate four words in both neural or interference trials by pressing the right middle finger. Task finalized with a fixation cross with $30 \mathrm{sec}$ duration. Amount of correct responses were assessed in each participant.

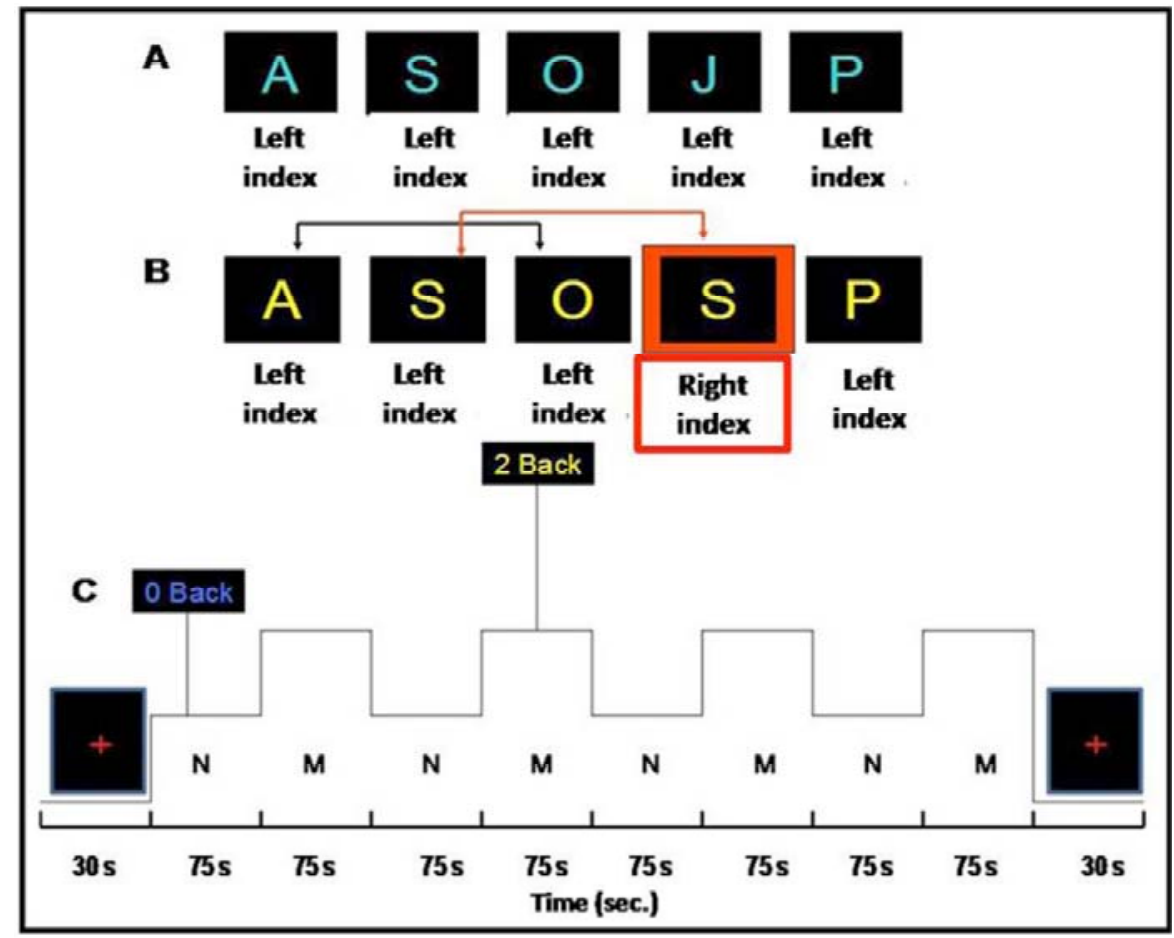

Fig. (2). Representation of the $N$-Back paradigm. A and $\mathbf{B}$ represent the kind of stimuli applied. (A) Letters in blue represent the neutral stimuli included in the 0 -Back series which the participant indicated with the movement of his index finger by the IFIS system (In Vivo Inc. Orlando FL) every time a letter was projected in the screen. (B) Letters in yellow represent the working memory condition in series 2-Back in which the participant indicated with the movement of the right index finger when the letter was projected two previous trials and with the left index finger when the letter was not projected in two previous trials. (C) Four blocks were presented in and alternated manner in each condition, with duration of 75 second per block. Each letter was projected during $500 \mathrm{~ms}$ followed by a fixation cross during $2500 \mathrm{~ms}$. 
Table 1. Brain Activations Identified at $\mathbf{p} \leq .05$ with Family Wais Error Correction while Executing the Counting Stroop Task to Assess Attention and Inhibition and the N-Back Paradigm to Assess Working Memory

\begin{tabular}{|c|c|c|c|c|c|c|}
\hline Brain Region & Laterality & Brodmann Area & Z Value & \multicolumn{3}{|c|}{ MNI Coordinates } \\
\hline \multicolumn{7}{|l|}{ Attention/Inhibition } \\
\hline Middle Frontal Gyrus & $\mathrm{L}$ & 46 & 4.5 & -52 & 28 & 26 \\
\hline Inferior Frontal gyrus & $\mathrm{D}$ & 9 & 3.7 & 60 & 18 & 26 \\
\hline Inferior Parietal Lobule & $\mathrm{D}$ & 40 & 3.93 & 44 & -46 & 54 \\
\hline Inferior Parietal Lobule & $\mathrm{L}$ & 40 & 3.63 & -48 & -40 & 46 \\
\hline Superior Temporal Gyrus & $\mathrm{L}$ & 22 & 3.6 & -62 & -42 & 12 \\
\hline Cuneus & $\mathrm{L}$ & 19 & 2.77 & -6 & -88 & 38 \\
\hline Inferior Frontal gyrus & $\mathrm{L}$ & 47 & 3.99 & -36 & -28 & -4 \\
\hline Superior Parietal Lobule & $\mathrm{R}$ & 7 & 5.05 & 30 & -70 & 54 \\
\hline Middle Temporal Gyrus & $\mathrm{R}$ & 22 & 4.18 & 62 & -38 & 4 \\
\hline Middle Temporal Gyrus & $\mathrm{L}$ & 21 & 3.99 & -64 & -28 & -4 \\
\hline Cuneus & $\mathrm{L}$ & 18 & 5.13 & -26 & -80 & 28 \\
\hline
\end{tabular}

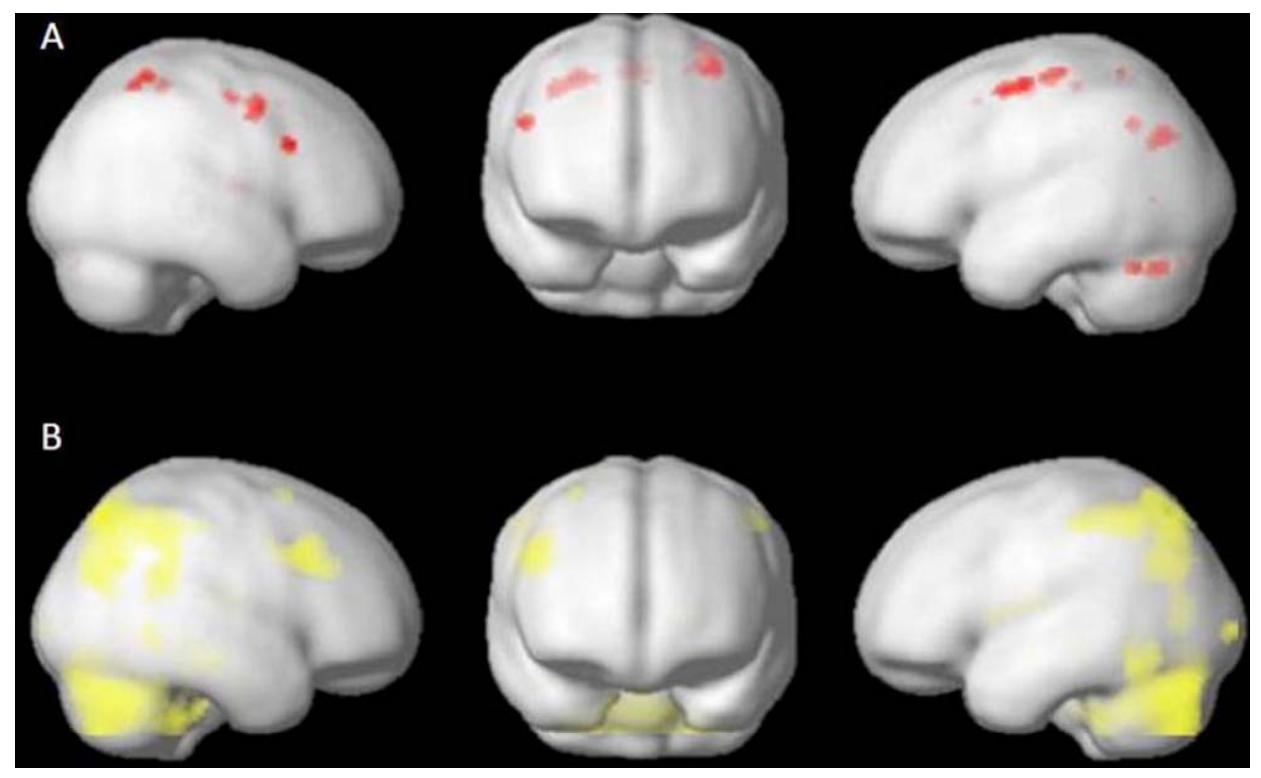

Fig. (3). Cortical surface in lateral and frontal views to illustrate the brain activity identified while execution of the Counting Stroop Task (A) and the N-Back paradigm (B).

while temporal activation suggest intermediate processes linked with long term memory formation (Baddeley, 2003). The whole brain activity identified in police officers coincide with that reported in civilian healthy samples while making working memory processes (Owen, McMillan, Laird, \& Bullmore, 2005) and decisions making based on this mnemonic information (Scalf, et al., 2011). So, prolonged stress and sleep deprivation conditions may affect working memory execution but not the elemental neurocognitive activity related.

Both cognitive paradigms applied represent indirect measures of inhibition processes. Since frontal activity has been related with moral learning and judgments (Anderson, Bechara, Damasio, Tranel, \& Damasio, 1999; Greene, 
Nystrom, Engell, Darley, \& Cohen, 2004) and neural inhibition of aggressive behaviors (Nelson \& Trainor, 2007), the activity in this brain region could represent the inhibitory pathways of impulsivity through the legal and moral codes acquired during the police training and practice. Examples of these codes are represented in the officer's ethnographic results by the officers when mention the helping behavior and social responsibilities as part of their basic traits. The inhibitory system shown by this police sample is correlated with the medium scores manifested in the Plutchik Impulsivity test in the larger sample. In addition, although differences in impulsivity have been attributable to sex variables (Bradley, Codispoti, Sabatinelli, \& Lang, 2001; Cross, et al., 2011) the lack of gender differences measured here suggest that the police training and practice may result in an equivalent behavior in women and men.

\section{CONCLUSIONS}

Neuroimaging has constituted a technique to identify neural substrates presented during basic cognitive processes. Police population usually relation with presents sleep deprivation due to rotary schedule, this deprivation is classically related with alterations in prefrontal activity, nevertheless brain activation identified in our police sample reflects a normal functional cognitive system. Maintenance of prefrontal activity even in sleep deprived and stressed conditions could imply the participation of this frontal region in several processes required for policing functions, such as a constant alerting system implicating the own and other's safety, suggesting these exacerbated attentional tasks result in a protected brain frontal function.

Aggressive situations manifested by policemen may not be related with impulsive factors but with the perception of injustice in the hierarchal organization of the institution. Even though this work reports an exploratory observation, the integrative method applied could represent an alternative to evaluate the neurocognitive function involving aggression in public servants and the interpretation of this process through the own participants' perception of reality obtained by the ethnological assessment. Therefore, interventional programs to reduce unwanted behaviors may be designed in a more accurate manner when supported by better neurocognitive and ethnological testing.

\section{ACKNOWLEDGEMENTS}

This study was supported by the financial contribution of the Municipality of Ciudad Nezahualcóyotl, México, and the scholarship CONACY No. 213635. We thank Fernando Galindo, Universidad Autónoma de Querétaro, Sarael Alcauter Solórzano, National Institute of Psychiatry and Leopoldo González-Santos and Juan J. Ortiz, Institute of Neurobiology, Universidad Nacional Autónoma de México, for technical support. We also thank the operational facilities provided by Mr. Jorge Amador Amador, Director of the Department Public Safety of Ciudad Nezahualcóyotl and the police officers who voluntary agreed to participate in this research.

\section{CONFLICT OF INTEREST}

None.

\section{REFERENCES}

Adolphs, R. (2008). The Social Brain: Neural Basis of Social Knowledge. Annual Review of Psychology 60, 18.11-18.24.

Aguiar, J. C. (2006). Las políticas de seguridad pública en América Latina: policía, violencia y narcotráfico en México. European Review of Latin American and Caribbean Studies 81, 115-121.

Alcazar-Corcoles, M. A., Verdejo-Garcia, A., Bouso-Saiz, J. C., \& BezosSaldana, L. (2010). Neuropsicología de la agresión impulsiva. Revista de Neurología 50 (5), 291-299.

Alexander, D. A., \& Walker, L. G. (1994). A study of methods used by Scottish police officers to cope with work-induced stress. Stress Medicine 10 (2) 131-138.

Amodio, D. M., Jost, J. T., Master, S. L., \& Yee, C. M. (2007). Neurocognitive correlates of liberalism and conservatism. Nature Neuroscience 10 (10), 1246-1247.

Anderson, S. W., Bechara, A., Damasio, H., Tranel, D., \& Damasio, A. R. (1999). Impairment of social and moral behavior related to early damage in human prefrontal cortex. Nature Neuroscience 2 (11), 10321037.

Arce, E., \& Santisteban, C. (2006). Impulsivity: a review. Psicothema 18 (2), 213-220.

Azaola, E. (2006). Imagen y autoimagen de la policía de la Ciudad de México. México D.F.: Ediciones Coyoacán.

Baddeley, A. (2003). Working memory: looking back and looking forward. Nature Review Neuroscience 4 (10), 829-839.

Barth, M. B., Kellner, K., \& Heinze, J. (2010). The police are not the army: context-dependent aggressiveness in a clonal ant. Biology Letters 6 (3), 329-332.

Berkowitz, L. (2008). On the consideration of automatic as well as controlled psychological processes in aggression. Aggressive Behavior 34 (2), 117-129.

Bradley, M. M., Codispoti, M., Sabatinelli, D., \& Lang, P. J. (2001). Emotion and motivation II: sex differences in picture processing. Emotion 1 (3), 300-319.

Buckner, R. L., Kelley, W. M., \& Petersen, S. E. (1999). Frontal cortex contributes to human memory formation. Nature Neuroscience 2 (4), 311-314.

Bush, G., Frazier, J. A., Rauch, S. L., Seidman, L. J., Whalen, P. J., Jenike, M. A., Rosen, B. R., Biederman, J. (1999). Anterior cingulate cortex dysfunction in attention-deficit/hyperactivity disorder revealed by fMRI and the Counting Stroop. Biological Psychiatry 45 (12), 1542-1552.

Bush, G., Whalen, P. J., Rosen, B. R., Jenike, M. A., McInerney, S. C., \& Rauch, S. L. (1998). The counting Stroop: an interference task specialized for functional neuroimaging--validation study with functional MRI. Human Brain Mapping 6 (4), 270-282.

Bush, G., Whalen, P. J., Shin, L. M., \& Rauch, S. L. (2006). The counting Stroop: a cognitive interference task. Nature Protocol 1 (1), 230-233.

Campbell, R. (1995). The role of work experience and individual beliefs in police officers' perceptions of date rape: an integration of quantitative and qualitative methods. The American Journal of Community Psychology 23 (2), 249-277.

Cohen, J. D., Dunbar, K., \& McClelland, J. L. (1990). On the control of automatic processes: a parallel distributed processing account of the Stroop effect. Psychological Review 97 (3), 332-361.

Cross, C. P., Copping, L. T., \& Campbell, A. (2011). Sex differences in impulsivity: a meta-analysis. Psychological Bulletin 137 (1), 97-130.

Cruz, L. C. (2007). Seguridad Pública (2 ed.). México D.F.: Trillas.

D'Andrade, R. G. (2001). A cognitivist's view of the units debate in cultural anthropology. Cross-Cultural Research 35 (2), 242-257.

Escalante, F. (2009). Homicidios 1990-2007. Nexos, 25-31.

Gansler, D. A., Lee, A. K., Emerton, B. C., D'Amato, C., Bhadelia, R., Jerram, M., et al. (2011). Prefrontal regional correlates of self-control in male psychiatric patients: Impulsivity facets and aggression. Psychiatry Research 191 (1), 16-23.

Gohar, A., Adams, A., Gertner, E., Sackett-Lundeen, L., Heitz, R., Engle, R., et al. (2009). Working memory capacity is decreased in sleepdeprived internal medicine residents. Journal of Clinical Sleep Medicine 5 (3), 191-197.

Greene, J. D., Nystrom, L. E., Engell, A. D., Darley, J. M., \& Cohen, J. D. (2004). The neural bases of cognitive conflict and control in moral judgment. Neuron 44 (2), 389-400.

James, A. S., Groman, S. M., Seu, E., Jorgensen, M., Fairbanks, L. A., \& Jentsch, J. D. (2007). Dimensions of impulsivity are associated with poor spatial working memory performance in monkeys. The Journal of Neuroscience 27 (52), 14358-14364. 
Koski, L., \& Paus, T. (2000). Functional connectivity of the anterior cingulate cortex within the human frontal lobe: a brain-mapping metaanalysis. Experimental Brain Research 133 (1), 55-65.

Mearns, J., \& Mauch, T. G. (1998). Negative mood regulation expectancies predict anger among police officers and buffer the effects of job stress. The Journal of Nervous and Mental Disease 186 (2), 120-125.

Meffert, S. M., Metzler, T. J., Henn-Haase, C., McCaslin, S., Inslicht, S., Chemtob, C., et al. (2008). A prospective study of trait anger and PTSD symptoms in police. Journal of Traumatic Stress 21 (4), 410-416.

Mercadillo, R.E., Díaz, J.L., Barrios F.A. (2007). Neurobiología de las emociones morales. Sald Mental, 30 (3), 1-11.

Mercadillo, R.E., Sánchez-Rey, A.E., Sánchez-Cortazar, J., Ramírez, E., \& Barrios, F.A. (2011) Resonancia magnética funcional en el diagnóstico cínico del déficit de atención y de la agresión impulsiva infantil: Una propuesta exploratoria. Salud Mental 34 (1), 11-20.

Nelson, R. J., \& Trainor, B. C. (2007). Neural mechanisms of aggression. Nature Review Neuroscience 8 (7), 536-546.

Neylan, T. C., Metzler, T. J., Best, S. R., Weiss, D. S., Fagan, J. A., Liberman, A., et al. (2002). Critical incident exposure and sleep quality in police officers. Psychosomatic Medicine 64(2), 345-352.

O'Donohue, W. T., \& Ferguson, K. E. (2003). Handbook of Professional Ethics for Psychologists: Issues, Questions, and Controversies. U.S.A.: Sage Publications Inc.

Owen, A. M., McMillan, K. M., Laird, A. R., \& Bullmore, E. (2005). Nback working memory paradigm: a meta-analysis of normative functional neuroimaging studies. Human Brain Mapping 25 (1), 46-59.

Páez, F., Jiménez, A., López, A., Raull-Ariza, J. P., Ortega-Soto, H., \& Nicolini, H. (1996). Estudio de validez de la traducción al castellano de la Escala de Impulsividad de Plutchik Salud Mental 19 (s. 3), 10-12

Pancheri, P., Martini, A., Tarsitani, L., Rosati, M. V., Biondi, M., \& Tomei, F. (2002). Assessment of subjective stress in the municipal police force of the city of Rome. Stress and Health 18 (3), 127-132.

Plutchik, R., \& Van Praag, H. (1989). The measurement of suicidality, aggressivity and impulsivity. Progress in Neuro-Psychopharmacology and Biological Psychiatry 13, S23-34.

Posner, M. I., Rothbart, M. K., Sheese, B. E., \& Tang, Y. (2007). The anterior cingulate gyrus and the mechanism of self-regulation. Cognitve, Affective and Behavioral Neuroscience 7 (4), 391-395.
Posner, M. I., Sheese, B. E., Odludas, Y., \& Tang, Y. (2006). Analyzing and shaping human attentional networks. Neural Networks 19 (9), 14221429.

Raichle, M. E. (2001). Cognitive neuroscience. Bold insights. Nature 412 (6843), 128-130.

Ramírez, J. M. (2003). Human aggression: A multifaceted phenomenon. Madrid: Centreur.

Ramírez, J. M., \& Andreu, J. M. (2006). Aggression, and some related psychological constructs (anger, hostility, and impulsivity); some comments from a research project. Neuroscience and Biobehavioral Reviews 30 (3), 276-291.

Ronald, S., Curtis, D., \& Isaacs, G. (1994). Psychiatric morbidity in policemen and the effect of brief psychotherapeutic intervention - a pilot study. Stress Medicine 10 (3), 151-157.

Santos, C. O., Caeiro, L., Ferro, J. M., Albuquerque, R., \& Luisa Figueira, M. (2006). Anger, hostility and aggression in the first days of acute stroke. European Journal of Neurology 13 (4), 351-358.

Scalf, P. E., Dux, P. E., \& Marois, R. (2011). Working Memory Encoding Delays Top-Down Attention to Visual Cortex. Journal of Cognitive Neuroscience, doi:10.1162/jocn.2011.21621

Sociedad Mexicana de Psicología. (2009). Código Ético del Psicólogo. México D.F.: Trillas.

Stuart, H. (2008). Suicidality among police. Current Opinion in Psychiatry 21 (5), 505-509.

Suárez de Garay, M. (2006). Los policías: una averiguación antropológica. Guadalajara, Méx: ITESO.

Terrill, W., Paoline, E. A., \& Manning, P. K. (2003). Police culture and coercion. Criminology 41 (4), 1003-1034.

Todorov, A., Harris, L. T., \& Fiske, S. T. (2006). Toward socially inspired social neuroscience. Brain Research 1079 (1), 76-85.

Upton, D. J., Bishara, A. J., Ahn, W. Y., \& Stout, J. C. (2011). Propensity for risk taking and trait impulsivity in the Iowa Gambling Task. Personality and Individual Differences 50 (4), 492-495.

Varela, S. E. (2007). Entrenamiento policial. México D.F.: Trillas.

Vaughn, M. G., Howard, M. O., \& Delisi, M. (2008). Psychopathic personality traits and delinquent careers: an empirical examination. International Journal of Law and Psychiatry 31 (5), 407-416.

(C) Mercadillo and Barrios; Licensee Bentham Open.

This is an open access article licensed under the terms of the Creative Commons Attribution Non-Commercial License (http://creativecommons.org/licenses/by-nc/3.0/) which permits unrestricted, non-commercial use, distribution and reproduction in any medium, provided the work is properly cited. 